\title{
GORLIN GOLTZ SYNDROME: A CASE REPORT
}

\author{
Nermine Ramadan * and Yasser F. Habaka **
}

\begin{abstract}
Gorlin-Goltz syndrome, also known as nevoid basal cell carcinoma syndrome, being due to a genetic alteration which produced by mutation in the "Patched" tumor suppressor gene, and it is inherited in an autosomal dominant way. This syndrome is about multisystemic process that is characterized by the presence of multiple pigmented basocellular carcinomas, odontogenic keratocysts in the jaws, palmar and/or plantar pits and calcification of falx cerebri. Together with these major features a great number of processes considered as minor features have also been described which include numerous skeletal, dermatological and neurological anomalies among others. Due to the importance of oral and maxillofacial manifestations of this syndrome, it is fundamental to know its characteristic in order to make a diagnosis, an early preventive treatment and establish right genetic advice.
\end{abstract}

KEY WORDS: Gorlin-Goltz, basocellular carcinoma, odontogenic keratocysts

\section{INTRODUCTION}

Gorlin and Goltz first described the spectrum of features which are associated with the Gorlin-Goltz syndrome or the Nevoid Basal Cell Carcinoma Syndrome (NBCCS). It is an autosomal dominant disorder with a genetic locus on chromosome subbands and bands 9q22.3-q31, as determined with linkage analysis ${ }^{[1]}$.

It is also called as the fifth phakomatosis due to the presence of multiple cutaneous, skeletal, ophthalmic and neurological abnormalities. It comprises of skeletal features such as the bifid rib, frontal, parietal bossing, mandibular prognanthism and cutaneous abnormalities such as multiple basal cell carcinomas and palmar and plantar keratosis. NBCCS can also include concomitant hypertelorism, mental retardation, strabismus, calcification of falx cerebri and medullo-blastomas ${ }^{[2]}$.

\section{Genetic aspects:}

The tumor suppressor gene called Patched (PTCH), located in the $9 \mathrm{q} 22.3$ chromosome, has been identified as the cause of Gorlin-Goltz syndrome ${ }^{(2-7)}$. This gene is composed of 23 exons

* Lecturer Oral And Maxillofacial Surgery, Oral Surgery Department, October 6 University

**Assistant Lecturer Oral And Maxillofacial Surgery, Oral Surgery Department, October 6 University 
and codifies a trans-membrane glycoproteins composed of 1447 amino acids and 12 domains ${ }^{(2-7)}$. This protein can be found in the Hedgehog signaling pathway. (6-8). When Hedgehog is absent, the family of PTCH trans-membrane receptors inhibits the protein that emits the Smoothened (SMO) signal. On the contrary, when Hedgehog combines PTCH, SMO signal is released, causing the activation of certain genes such as GLI1, PTCH 1, CCND2, FOXL1 and $\mathrm{JAG}^{(9,10)}$.

Gorlin-Goltz syndrome is produced due to mutation in this gene, with loss of heterozygosity ${ }^{(4-7)}$. This loss has also been observed in basocellular carcinomas without any relation to the syndrome, in the meduloblastoma and in odontogenic keratocysts ${ }^{(6)}$. Nearly $40 \%$ of the syndrome cases present as new mutations ${ }^{(4,6,7)}$.

Patients suffering from Gorlin-Goltz syndrome show an important variability in their phenotype, it has been observed that individuals with the same molecular alterations present very different symptoms ${ }^{(11)}$. The fact that there is no relationship between the genotype and the phenotype in this syndrome suggests the existence of a very complex variability of the phenotype ${ }^{(4)}$. This variation is thought to be originated due to the interaction of genetic and environmental factors ${ }^{(2,4)}$.

\section{Clinico-pathological aspects:}

In order to make a diagnosis of the Gorlin Goltz syndrome some diagnosis criteria have to be taken into account. The most important criteria to make a diagnosis for this syndrome are the presence of pigmented baso-cellular carcinomas, odontogenic keratocysts, palmar and/or plantar pits and ectopic calcifications of falx cerebri ${ }^{(1-4,6,8-11)}$.

Together with these major features more than
100 minor features have been described. The more relevant features are the following: cardiac or ovarian fibroma, macroencephaly, bifid ribs, cyphoscoliosis, cleft palate, medulloblastoma (1-2\% is attributed to the syndrome and from 3 to $5 \%$ is the incidence in this syndrome), alterations in the sella turcica, mandibular prognathia, lateral displacement of the inner canthus, frontal and biparietal bossing, imperfect segmentation of the cervical vertebrae, linfomesenteric cysts that tend to calcify, meningiomas, fibrosarcoma, rhabdomyosarcoma, short fourth metacarpal, strabismus, ocular hypertelorism, congenital blindness, spina bifida occulta, pectum excavatum, high arched eyebrows and palate, narrow sloping shoulders, immobile thumbs, low pitch voice in women, renal anomalies and hypogonadism in men ${ }^{(2,3,8,10,11)}$.

In certain occasions, a tall height and even similar characteristics to acromegaly have been associated with the syndrome ${ }^{(3)}$. There are two options to make a correct diagnosis of the Gorlin-Goltz syndrome, or two major features and one minor feature ${ }^{(33)}$. In table (1), the main alterations that have been described in relation to this syndrome are presented. The odontogenic keratocysts represent from 3 to $15 \%$ out of the total number of odontogenic cysts ${ }^{(9)}$ and they appear in the $65-75 \%$ of the cases of the syndrome ${ }^{(1,3,10,11)}$. These cysts represent a particular entity that has been of interest, mainly due to biological aggressiveness and to the great amount of recurrence ${ }^{(1,7-11)}$. Recently and based on the intrinsic growth potential of its epithelial coating, they have been re-classified and called odontogenic keratocyst tumors, and they have been included in the odontogenic neoplasias ${ }^{(7,11)}$. In table (2), different manifestations of the basocellular carcinomas depending on whether they are associated to the Gorlin-Goltz syndrome or not..$^{(8-13)}$ 
TABLE (1) Anomalies described in Gorlin Goltz Syndrome: (3,10-13)

\begin{tabular}{|c|c|c|}
\hline \multicolumn{3}{|c|}{ SKELETAL ANOMALIES } \\
\hline Bridging sella turcica $(60-80 \%)$ & \multicolumn{2}{|c|}{ Hemivertebrae } \\
\hline Scoliosis $(50 \%)$ & \multicolumn{2}{|c|}{ Flatfoot } \\
\hline Shortened 4th metacarpal & \multicolumn{2}{|c|}{ Bifid rib (40\%) } \\
\hline Syndactyly and/or oligodactyly & \multicolumn{2}{|c|}{ Splayed/fused ribs } \\
\hline Occult bifid rib (cervical, thoracic or both of which $40 \%$ ) & \multicolumn{2}{|c|}{ Pelvic calcification } \\
\hline Another: arachnodactyly, hallux valgus, cortical defects in long bones. & \multicolumn{2}{|c|}{ Cervical ribs } \\
\hline Absent ribs $(26 \%)$ & \multicolumn{2}{|c|}{ Sprengel scapular deformity } \\
\hline \multicolumn{3}{|l|}{ Pectum excavatum, carinatum } \\
\hline \multicolumn{3}{|c|}{ SKIN ANOMALIES } \\
\hline \multicolumn{2}{|l|}{ Basal cell carcinoma $(50-97 \%)$} & Milia, specially in limbs \\
\hline Palmar and/or plantar pits $(60-90 \%)$ & \multicolumn{2}{|r|}{ Comedones } \\
\hline \multicolumn{3}{|c|}{ CRANIOFACIAL ANOMALIES } \\
\hline \multicolumn{2}{|l|}{ Calcification of the cerebral falx $(37-79 \%)$} & Brachycephaly \\
\hline \multicolumn{2}{|l|}{ Macrocephaly (40\%) } & Bridged in sella turcica \\
\hline \multicolumn{2}{|l|}{ Tentorium cerebellum calcification } & Frontal bossing $(25 \%)$ \\
\hline Coroidal cysts $\left(3^{\circ}-4^{\circ}\right.$ ventricles $)$ & \multicolumn{2}{|r|}{ Coarse face } \\
\hline \multicolumn{3}{|c|}{ SEXUAL ANOMALIES } \\
\hline \multicolumn{2}{|l|}{ Uterine and ovarian fibromas (15\%) } & Supernumerary nipple \\
\hline Ovarian fibrosarcoma & \multicolumn{2}{|r|}{ Calcified ovarian cysts } \\
\hline \multicolumn{2}{|l|}{ Female distribution of the pubis hair, Scarce beard in men and ginecomastia. } & Hypogonadism and \\
\hline $\begin{array}{l}\text { NEUROLOGICAL ANO } \\
\end{array}$ & MALI & IES \\
\hline Medulloblastoma (3-5\%) & & Meningioma (1\% or less) \\
\hline Agenesis/ disgenesis of corpus callosum & & Schizophrenic personality \\
\hline Mental retardation & & Nervous deafness \\
\hline Congenital hydrocephalus & & Anosmia \\
\hline OPHTHALMIC ANON & ALIE & \\
\hline Hypertelorism (40\%) & & Glaucoma \\
\hline Exotropia & & Ptosis \\
\hline Choroidal and/or optic nerve coloboma & & Congenital amaurosis \\
\hline Congenital blindness and opaque cornea & & Cataracts \\
\hline Internal strabismus (15\%) convergent / divergent Chalazion & & \\
\hline OROFACIAL ANOMALIES & & \\
\hline Odontogenic keratocysts $(75 \%)$ & & Palate or maxillary sinus fibroma \\
\hline High-arched palate or prominent palatine ridges $(40 \%)$ & & $\begin{array}{l}\text { Malocclusion (maxillary and mandibular } \\
\text { hyperplasia and hypoplasia) }\end{array}$ \\
\hline Cleft lip and/or palate (4\%) & & Fibrosarcoma of the jaws \\
\hline Impacted teeth and/or agenesis. & & Dental ectopic position. \\
\hline Ameloblastoma & & \\
\hline
\end{tabular}


TABLE (2) Different manifestations of the basocellular carcinomas depending on whether they are associated to the Gorlin-Goltz syndrome or not.(8-13)

\begin{tabular}{|l|l|l|}
\hline DATA & $\begin{array}{l}\text { Basocellular carcinoma no-assoaciated to the } \\
\text { Gorlin-Goltz Syndrome }\end{array}$ & $\begin{array}{l}\text { Basocellular carcinoma associated to the GorlinGoltz } \\
\text { Syndrome }\end{array}$ \\
\hline Number & Only one & 50 to 100 \\
\hline Sex & More frequent in men & Equally frequency in both of the sex \\
\hline Location & Half third facial & $\begin{array}{l}\text { Face, neck, back, thorax, abdomen and upper part of } \\
\text { the body }\end{array}$ \\
\hline $\begin{array}{l}\text { Clinical } \\
\text { characteristics }\end{array}$ & $\begin{array}{l}\text { Papulae }>>\text { central ulceration Variable colour } \\
\text { More frequent in white skins }\end{array}$ & $\begin{array}{l}\text { Small papulaes, soft nodule or a plane plaque. } \\
\text { Variable colour pink >> brown Any colour of skin }\end{array}$ \\
\hline Etiology & Solar radiation & Genetically determinated \\
\hline Treatment & It depends on the size and the location & Surgery \\
\hline & Surgery & Risk to develop new injuries \\
\hline
\end{tabular}

\section{Patient and method:}

A 14 year old male reported to the OPD of our department with the complaint of unerrupted teeth and malocclusion. An intra-oral examination revealed missing both upper and lower left canine, upper right canine and first \& second premolars. On general examination, the patient was found to be well built and his face showed frontal bossing, hypertelorism and prominent supra-orbital ridges (Fig 1).

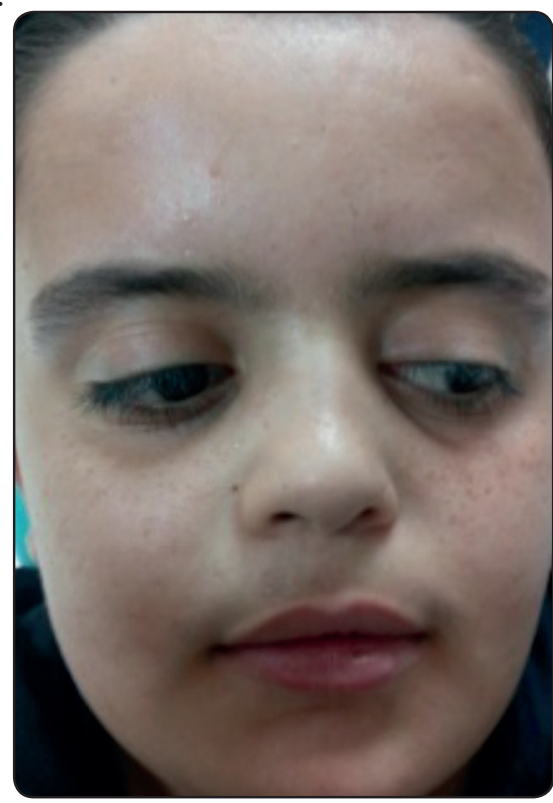

Fig. (1) Showing frontal bossing and prominent supra-orbital ridges

\section{Diagnostic aspects}

An Orthopantomogram (OPG) of the patient showed multiple cysts in the jaws - one in the mandible and one in the maxilla (Fig 2). Considering the possibility of the Gorlin- Goltz syndrome, further evaluation was done with chest radiographs, which revealed a bifid rib (Fig 3),

\section{Therapeutic aspects}

The treatment of Gorlin-Goltz syndrome is the specific therapeutics of its clinical manifestations. In the case of odontogenic keratocysts, there are different treatment techniques to eliminate them and

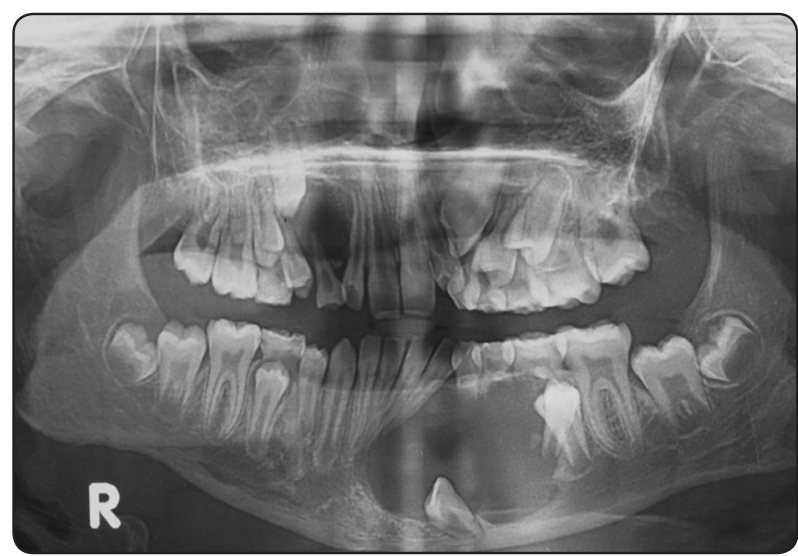

Fig (2) panoramic radiograph showing cystic lesion related to impacted maxillary right canine and impacted mandibular left canine. 


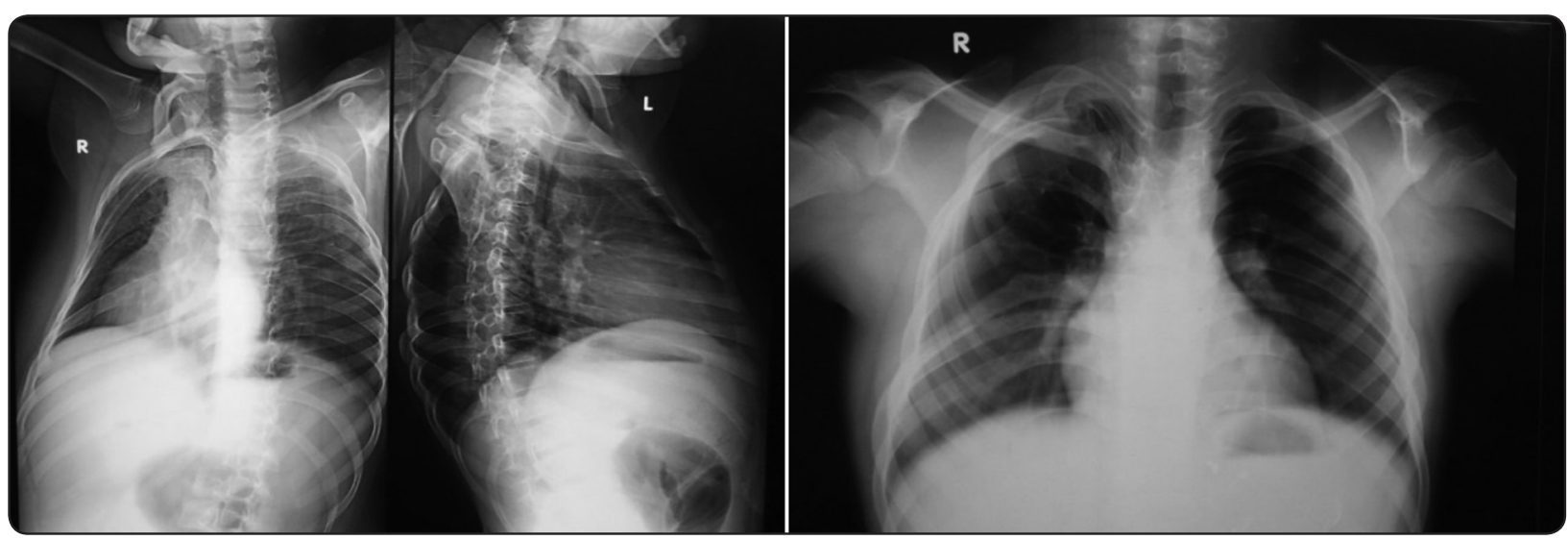

Fig (3) Chest radiograph showing bifid rib

to avoid the high rate of recurrence, which can reach up to a $62 \%$ of the cases ${ }^{(1,7,10)}$.

The therapeutic techniques for the keratocysts vary from simple enucleation with curettage, to the enucleation with peripheral osteotomy or to osseous resection in block ${ }^{(1,10)}$. This last technique is the most aggressive and it logically follows that the recurrence rate decreases ${ }^{(8)}$. There are also more conservative options such as the local parietal therapy with Carnoy solution, with cryotherapy or marsupialisation of the cysts, or decompression followed by a secondary enucleation ${ }^{(9,10)}$.

Nevertheless, those methods are not efficient in the long term and their use is considered to be controversial ${ }^{(9,10)}$. In order to decide which technique must be employed, the following factors have to be taken into account: lesion size, lesion extension, location, possible cortical and soft parts damage, the age and whether it is a primary or recurrent lesion (8). It is also important to detect if it is an isolated keratocyst or if it is associated with the syndrome, since in the last case the rate of recurrence is higher as Reyes et al. ${ }^{(14)}$ have suggested- the recurrence rate is of $63 \%$ in keratocysts associated to the syndrome, and of $37 \%$ in the isolated ones ${ }^{(14)}$. As well as keratocysts, basocellular carcinomas treatment is also based on conventional surgical exeresis with or without reconstruction, or with other techniques such as $\mathrm{CO} 2$ laser ${ }^{(8,10)}$. In primary small and well defined lesions without aggressive behaviour, curettage, electrodissection and cryosurgery techniques have also been used.

However, these techniques have the problem of impeding the correct histopathological estimate of the samples and, hence, the biological estimate and the possible extension to the surgical margins-very usual piece of data in this pathology. In some plane superficial lesions which do not affect the hair follicle, photodynamic therapy with delta-aminolevulinic acid has been employed, as well as the topical application of 5 -fluorouracil to $0,1 \%$ (twice a day), or intralesional interferon alfa-2b or the chemotherapeutic paclitaxel agent ${ }^{(10)}$. Local radiation therapy would not be advisable because of the tumor recurrence risk or because of the possible tumor growth ${ }^{(10)}$.

In our case, marsupialization was done in the maxillary right lesion and mandibular left lesion (fig 4-6). On 9 months follow up we discovered a new lesion arises in the mandibular right third molar extended to ramus area. (Fig 5) Surgical enucleation of lesion with the removal of mandibular third molars of both sides. In addition, the use of Carnoy's solution following cyst enucleation (applied only over the areas where the cyst is attached to the mucosa) (fig 7)

The tissues were sent for histo-pathological examination and all the cysts were found to be odontogenic keratocysts. 


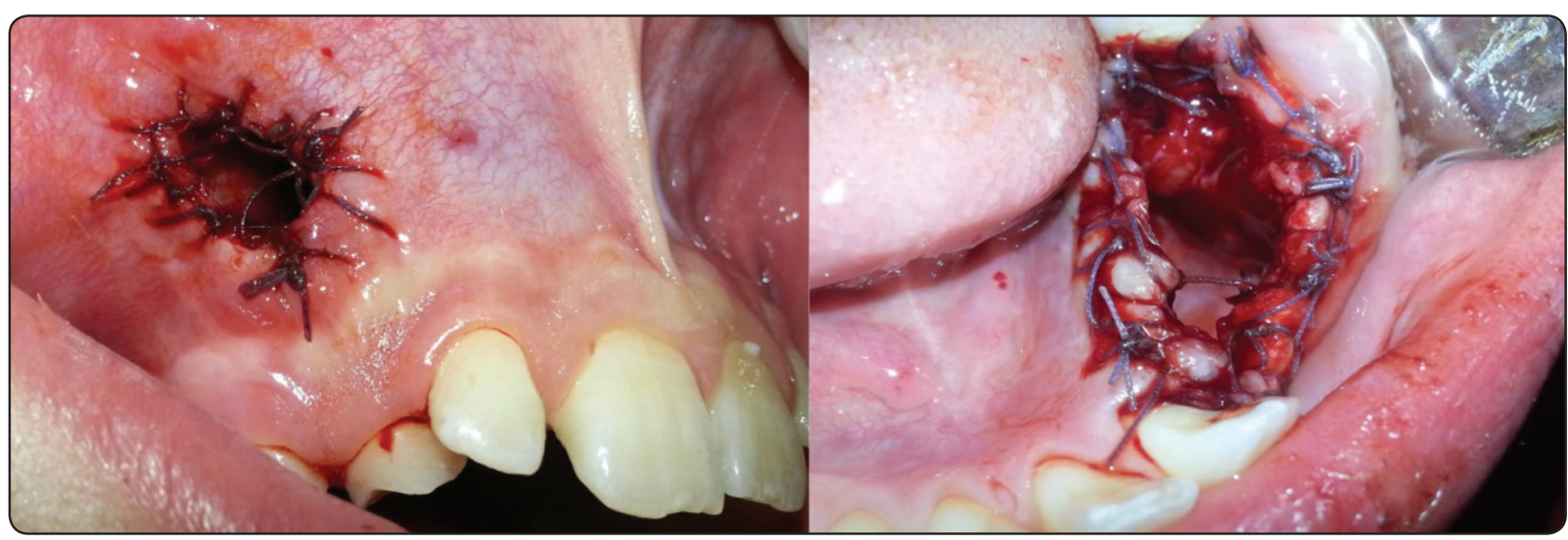

Fig (4) Showing marsupialization of both cysts in maxillary and mandibular canine-premolar areas

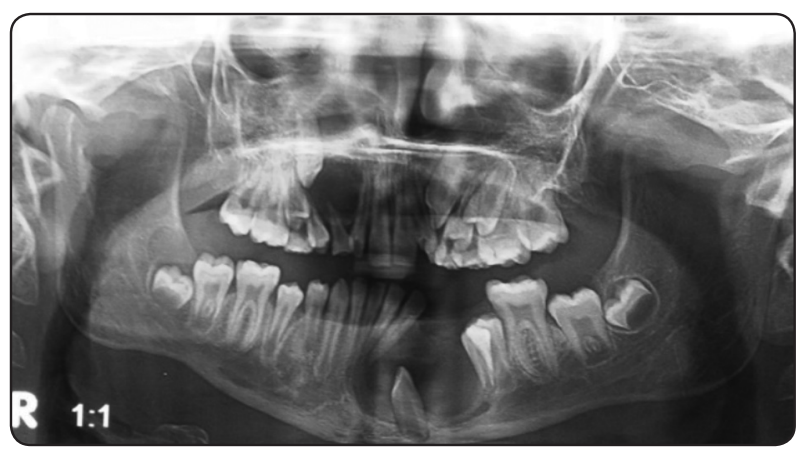

Fig (5) a) Preoperative radiograph showing impacted mandibular right canine and maxillary right canine

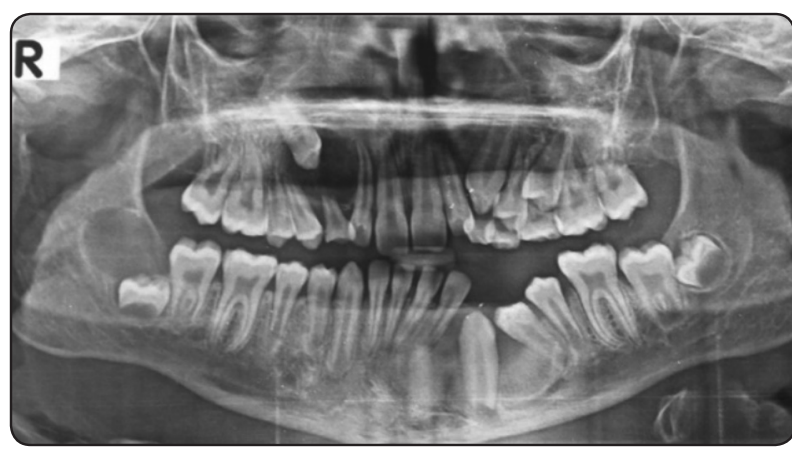

Fig (5) b) Post-operative panoramic radiograph showing the eruption of maxillary and mandibular canine after cyst marsupialization and the appearance of a new cystic lesion related to mandibular right third molar

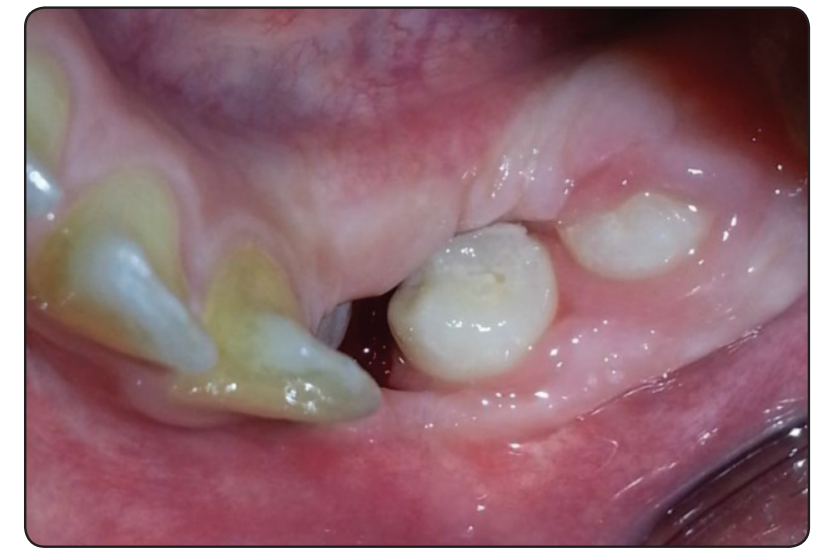

Fig (6) Clinical photograph showing the eruption of mandibular canine and premolar 


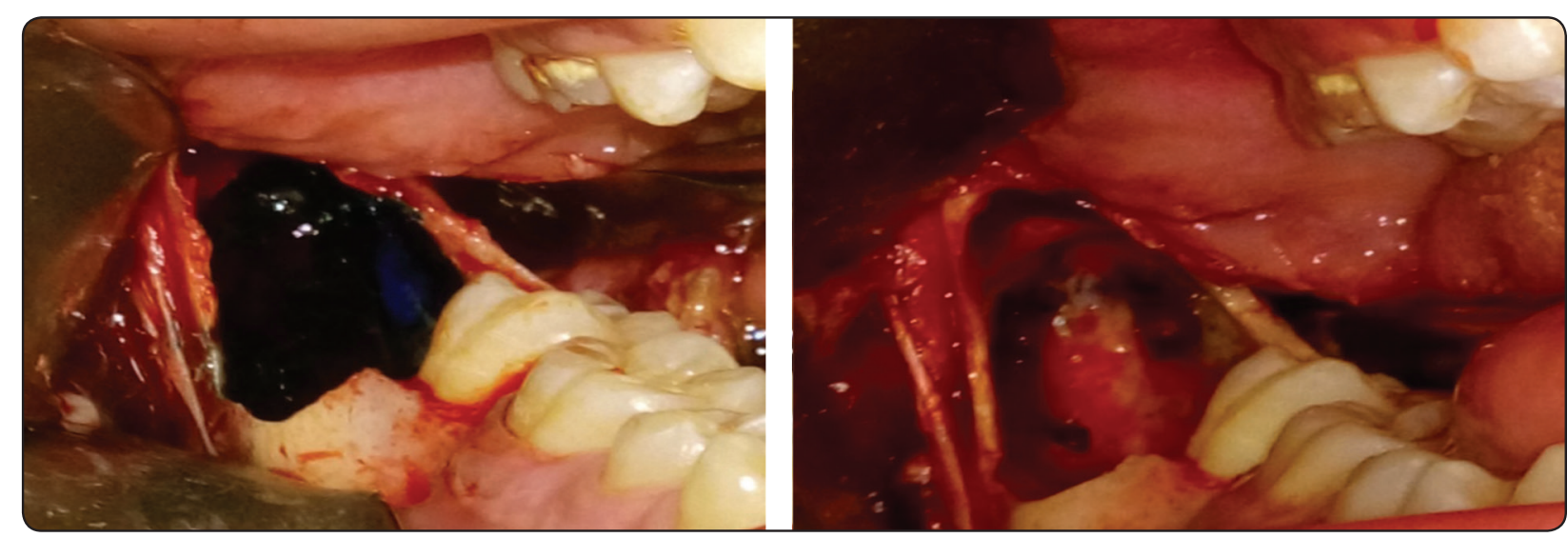

Fig (7) Intra-operative clinical photograph showing cyst enucleation related to mandibular third molar, with the application of carnoy's solution

\section{DISCUSSION}

The diagnosis of the Gorlin-Goltz syndrome is made clinically by using the criteria. Two major or one major and two minor criteria should be satisfied for a positive diagnosis ${ }^{(1-4,6,8-11)}$. This is in agreement with our patient who had two major features of NBCCS, namely bifid rib, multiple odontogenic keratocysts in the jaw and minor features such as frontal bossing, prominent supraorbital ridges and hypertelorism, thus suggesting it to be a case of the Gorlin-Goltz syndrome.

Regarding the site predilection, OKCs which are associated with NBCCS are more common in the mandible with $69 \%$ involvement, as compared to $31 \%$ in the maxilla. In the mandible, $43 \%$ OKCs occurs in the molar ramus region, followed by $18 \%$ in the incisor- $\neg$ canine area. In the maxilla, 14\% OKCs were found to occur in the incisor- $\neg$ canine area, followed by molar tuberosity with $12 \%, 7 \%$ in the mandibular premolar region and $3 \%$ in the maxillary premolar region. Regarding the male to female ratio, it was 1:0.62 for OKCs which were not associated with NBCCS and 1:1.22 for OKCs in NBCCS. This shows that simple keratocysts are more common in males, but that more females seem to have NBCCS ${ }^{(15)}$.
Our study was in agreement with Myoung et al who performed cystectomy, including the removal of the bony walls of the resulting cavity, is an adequate surgical treatment for the odontogenic keratocysts. In the treatment of the recurrent OKCs which are associated with NBCCS, the overlying surface epithelium should be excised along with the cystic lining to prevent recurrences from the residual epithelial islands and microcysts ${ }^{(16)}$. In addition, the use of Carnoy's solution following cyst enucleation (applied only over the areas where the cyst is attached to the mucosa) and cryosurgery (because of the unique ability of liquid nitrogen to devitalize the bone in situ while leaving the inorganic framework untouched) is advocated to kill the epithelial remnants and the dental lamina within the osseous structures and to thus, prevent recurrences ${ }^{(17)}$.

\section{CONCLUSION}

As a conclusion, it can be said that Gorlin-Goltz syndrome is an autosomal dominant genetic process. Our case highlights the importance of the awareness of this rare syndrome, especially in young patients without any skin lesions. It is useful to keep in mind the existence of this syndrome and to recognize the presence of some major criteria. When a patient has 
this syndrome is of relevant importance to examine their family to detect possible clinical manifestations and in that way arrive at effective genetic advice. Specialists should carry out a clinical radiographic testing in early ages of life, in order to be able to arrive at an early diagnosis of the syndrome. In this way, different health specialists play a key role: pediatricians, specialists in genetics, dentists, maxillofacial surgeons, and dermatologists must have good basic knowledge of the main features of the syndrome to work accordingly in their different health specialities.

\section{REFERENCES}

1. Gailani MR, Bale SJ, Leffell DJ, et al. Developmental defects in Gorlin syndrome related to a putative tumor suppressor gene on chromosome. Cell 69(1):111-7;1992.

2. Lindeboom JA, Kroon FH, de Vires J, van den Akker HP. Multiple recurrent and de novo odontogenickeratocysts associated with oral-facial-digital syndrome. Oral Surg Oral Med Oral Pathol Oral RadiolEndod 95(4):458$62 ; 2003$

3. Ramaglia L, Morgese F, Pighetti M, Saviano R. Odontogenic keratocyst and uterus bicornis in nevoid basal cell carcinoma syndrome: case report and literature review. Oral Surg Oral Med Oral Pathol Oral Radiol Endod. 102(2):217-9; Aug 2006

4. Boutet N, Bignon YJ, Drouin-Garraud V, Sarda P, Longy $\mathrm{M}$, Lacombe D et al. Spectrum of PTCH1 mutations in french patients with Gorlin syndrome. J Invest Dermatol. 121(3):478-81; Sep 2003

5. Pastorino L, Cusano R, Nasti S, Faravelli F, Forzano F, Baldo $\mathrm{C}$ et al. Molecular characterization of italian nevoid basal cell carcinoma syndrome patients. Hum Mutat. 25 (3):322-3; Mar 2005

6. Hooper JE, Scott MP. Communicating with Hedgehogs. Nat Rev Mol Cell Biol. 6 (4): 306-17; Apr 2005

7. Briscoe J, Therond P. Hedgehog signaling: from the Drosophila cuticle to anti-cancer drugs. Dev Cell. 8(2):143-51; Feb 2005
8. Katoh Y, Katoh M. Hedgehog signaling and gastric cancer. Cancer Biol Ther. 4(10):1050-4; Oct 2005

9. Hallikas O, Palin K, Sinjushina N, Rautiainen R, Partanen $\mathrm{J}$, Ukkonen E et al. Genome-wide prediction of mammalian enhancers based on analysis of transcription-factor binding affinity. Cell. 13;124(1):47-59; Jan 2006

10. Kasper M, Schnidar H, Neill GW, Hanneder M, Klingler S, Blaas L et al. Selective modulation of Hedgehog/GLI target gene expression by epidermal growth factor signaling in human keratinocytes. Mol Cell Biol. 26(16): 6283-98; Aug 2006

11. Wicking C, Shanley S, Smyth I, Gillies S, Negus K, Graham $\mathrm{S}$ et al. Most germ-line mutations in the nevoid basal cell carcinoma syndrome lead to a premature termination of the PATCHED protein, and no genotypephenotype correlations are evident. Am J Hum Genet. 60(1):21-6; Jan 1997

12. R Yang X, Pfeiffer RM, Goldstein AM. Influence of glutathione-Stransferase (GSTM1, GSTP1, GSTT1) and cytochrome p450 (CYP1A1, CYP2D6) polymorphims on numbers of basal cell carcinomas (BCCs) in families with the naevoid basal cell carcinoma syndrome. J Med Genet. 43 (4):e16; Apr 2006

13. Veenstra-Knol HE, Scheewe JH, van der Vlist GJ, van Doorn ME, Ausems MG. Early recognition of basal cell naevus syndrome. Eur J Pediatr. 164 (3):126-30; Mar 2005

14. Reyes Macias JF, Bagán Sebastián JV. Gorlin Goltz syndrome, review of literature. Case report. Rev Europ Odonto Estomatol. 14(2):105-12; Mar 2002

15. Karthiga S Kannan, Sivapatha B Sundharam, R Manikandan. Nevoid basal cell carcinoma syndrome. IJDR 17(1): 50-53; 2006

16. Myoung H, Hong SP, Hong SD, Lee JI, Lim CY, Choung $\mathrm{PH}$, and others. Odontogenickeratocyst: review of 256 cases for recurrence and clinico $\neg$ pathologic parameters. Oral Surg Oral Med Oral Pathol Oral Radiol Endod 91(3):328-33;2001

17. Stoelinga PJ. Excision of the overlying, attached mucosa, in conjunction with cyst enucleation and treatment of the bony defect with carnoy solution. Oral Maxillofac Surg Clin N Am 15:407-14; 2003 